\title{
Association of -786T-C mutation of endothelial nitric oxide synthase gene with insulin resistance
}

\author{
K. Ohtoshi, Y. Yamasaki, S. Gorogawa, R. Hayaishi-Okano, K. Node, M. Matsuhisa, Y. Kajimoto, \\ M. Hori \\ Department of Internal Medicine and Therapeutics, Osaka University Graduate School of Medicine, Suita City, Japan
}

\begin{abstract}
Aims/hypothesis. Endothelial derived nitric oxide synthase $(e N O S)$ gene polymorphisms affect $e N O S$ activity and are associated with abnormal vasomotility and impaired local blood flow. A decrease in local blood flow has been reported to cause insulin resistance. The aim of this study was to examine a possible association of two eNOS polymorphisms, Glu298Asp (G894T) in exon 7 and -786T-C mutation with insulin resistance.

Methods. Genotypes of both Glu298Asp and -786T-C mutation were examined by the PCR-RFLP method. Plasma nitrate and nitrite concentrations were also measured.

Results. The allele frequencies of both polymorphisms showed no considerable differences in 233 non-diabetic subjects and 301 patients with Type II (non-insulin-dependent) diabetes mellitus. Non-diabetic subjects with the $-786 \mathrm{C}$ allele had $(p<0.05)$ higher fasting plasma insulin and homeostasis model assessment of
\end{abstract}

insulin resistance than those with the $-786 \mathrm{~T} /-786 \mathrm{~T}$ genotype. Diabetic subjects with $-786 \mathrm{C}$ allele showed higher $\mathrm{HbA}_{1 \mathrm{c}}$ than those with the -786T/-786T genotype. A euglycaemic hyperinsulinemic clamp study done on 71 of the 301 patients showed a lower glucose infusion rate in diabetic patients with the $-786 \mathrm{C}$ allele than those without it. In diabetic patients with the -786C allele, plasma nitrate and nitrite concentrations were lower than in subjects without it $(p=0.026)$. No differences were observed between mutant carriers of Glu298Asp and non-carriers among both nondiabetic subjects and Type II diabetic patients.

Conclusions/interpretation. The -786T-C mutation of the $e N O S$ gene is associated with insulin resistance in both Japanese non-diabetic subjects and Type II diabetic patients. [Diabetologia (2002) 45:1594-1601]

Keywords Endothelial nitric oxide synthase, polymorphism, glucose infusion rate, homeostasis model assessment of insulin resistance insulin resistance, intima-media thickness.
Endothelial derived nitric oxide (NO), synthesized from L-arginine by the endothelium isoform of $\mathrm{NO}$ synthase (eNOS), mediates local vasodilation and plays

Received: 5 March 2002 / Revised: 19 June 2002

Published online: 9 October 2002

C) Springer-Verlag 2002

Corresponding author: Dr. Y. Yamasaki, Department of Internal Medicine and Therapeutics, Osaka University Graduate School of Medicine, 2-2 Yamadaoka, Osaka Pref. 565-0871, Japan. E-mail: yamasaki@medone. med.osaka-u.ac.jp

Abbreviations: NO, Nitric oxide; eNOS, endothelial derived nitric oxide synthase; HOMA IR, homeostasis model assessment of insulin resistance; NOx, nitrate and nitrite; GIR, glucose infusion rate; IMT, intima-media thickness. a key role in the regulation of vascular tone. Skeletal muscle glucose uptake is enhanced by insulin-mediated vasodilation and the decrease in local blood flow can result in insulin resistance [1-5]. However, several reports deny a major role of endothelial NO production in determining insulin sensitivity $[6,7]$.

Recently eNOS knockout mice have been reported to be insulin resistant [8]. These mice have also shown a decrease in whole-body and muscle-glucose uptake as well as the simultaneous decrease in the local blood flow [9]. Two major polymorphisms have been found in the human eNOS gene: Glu298Asp (G894T) in exon 7 and $-786 \mathrm{~T}-\mathrm{C}$ mutation in the $5^{\prime}$-flanking region. Glu298Asp causes a structural change of the eNOS 
protein and reduces eNOS activity [10, 11]. In contrast, the -786T-C mutation reduces the promoter activity [12] and thus reduces eNOS protein expression and eNOS activity [10]. Both Glu298Asp and -786T-C polymorphism have been reported to lead to abnormal vasomotility $[13,14]$ and to be associated with vasoconstrictive angina $[12,15]$. However, the association between both eNOS polymorphisms and insulin resistance has not been found.

\section{Subjects and methods}

Subjects. We recruited 301 Japanese patients with Type II (non-insulin-dependent) diabetes mellitus aged 30 to 76 years from a group of outpatients at the Osaka University Hospital. The assessment of Type II diabetes was based on World Health Organization (WHO) criteria [16]. Patients were recruited for the study if they met the following inclusion criteria: (i) no episodes of ketoacidosis and absence of ketonuria, (ii) diagnosis of diabetes after 30 years of age, (iii) insulin therapy (if any) started after at least 5 years following diagnosis, (iv) absence of overt diabetic nephropathy or other renal tract disease, and (v) absence of acute stage or signs and syndromes of coronary heart disease, cerebral vascular disease, and peripheral artery disease after careful evaluation of clinical records. The duration of diabetes was $12.0 \pm 9.2$ years.

We recruited 233 non-diabetic hospital employees as control subjects aged 21 to 66 years without cardiovascular disease, cerebrovascular disease, or peripheral vascular disease. Normal blood glucose concentrations in these subjects were assessed with the 75-g oral glucose tolerance test (OGTT) according to WHO criteria [16]. Written informed consent was obtained from all the subjects enrolled in this study.

At the time of enrolment, the laboratory data, blood pressure measurements, urinary albumin measurements, resting 12-lead ECG and master two-step test results, and intima plus media thickness (IMT) measurements were collected for each patient. Fasting blood was obtained for analysis of serum total cholesterol, HDL cholesterol, serum triglycerides, serum creatinine, blood urea nitrogen, serum uric acid, and $\mathrm{HbA}_{1 \mathrm{c}}$ concentrations by standard laboratory techniques. Urinary albumin of a fasting urine specimen and a specimen collected at least 4 weeks later was measured by radioimmunoassay. The concentration was divided by the urinary creatinine concentration and expressed as milligrams per gram of creatinine [17]. The two measurements of urinary albumin were averaged. Blood pressure was measured with a mercury sphygmomanometer (Model 620; Kenzmedico, Saitama, Japan). After a supine rest of $5 \mathrm{~min}$, three measurements in sitting position were conducted, and the mean value was used. Smoking was estimated as the mean number of cigarettes smoked daily. Checking for the occurrence of angina pectoris and old myocardial infarction (major abnormal Q wave or abnormal QS pattern changes) were based on the results of the resting 12-lead ECG and master two-step tests and the existence of previous symptoms of myocardial infarction. Of the 301 Type II diabetic patients, 73 patients were controlled with diet only, 117 patients with oral agents, and 111 patients with insulin injection.

Assessment of insulin sensitivity. Insulin sensitivity was assessed using fasting insulin and glucose concentrations by homeostasis model assessment of insulin resistance (HOMA IR) for non-diabetic patients [18]. Plasma insulin concentra- tions were measured by radioimmunoassay (SRL, Tokyo, Japan). Of Type II diabetic patients, 71, from whom agreement was obtained, were subjected to determination of insulinmediated glucose uptake by the euglycaemic hyperinsulinemic clamp technique using an artificial pancreas (STG22; Nikkiso, Tokyo, Japan) [19, 20]. Briefly, regular insulin (Humalin-R Eli Lilly, Indianapolis, Ind., USA) was infused in a primed continuous manner at a rate of $8.7 \mathrm{pmol} \cdot \mathrm{kg}^{-1} \cdot \mathrm{min}^{-1}$ for $2 \mathrm{~h}$. Normoglycaemia was maintained by adjusting the rate of a $10 \% \mathrm{D}$ glucose infusion based on plasma glucose measurements carried out at $1 \mathrm{~min}$ intervals. Glucose infusion rate (GIR) was calculated by averaging the glucose infusion rates achieved over the last $30 \mathrm{~min}$ of the clamp as endogenous glucose production is completely suppressed at the increased concentrations achieved. Before the clamp study, the patients were admitted to Osaka University Hospital for at least 2 weeks and were confirmed to be free of glucose toxicity.

Assessment of carotid atherosclerosis. Ultrasonographic scanning of the carotid arteries was done using an echotomographic system (EUB-450; Hitachi Medico, Tokyo Japan) with an electrical linear transducer (midfrequency of $7.5 \mathrm{MHz}$ ). Scanning of the extracranial common carotid artery, the carotid bulb, and the internal carotid artery in the neck was carried out bilaterally from three different longitudinal projections (i.e., anterior, lateral, and posterior-oblique) as well as the transverse projection, as reported previously [21-23]. All of the images were photographed. The scanning session lasted an average of $30 \mathrm{~min}$. The detection limit of this echo system using $7.5 \mathrm{MHz}$ was $0.1 \mathrm{~mm}$. The carotid IMT defined by another study [24] was measured as the distance from the leading edge of the first echogenic line to the leading edge of the second echogenic line. The first line represented the lumen-intimal interface and the second line the collagen-containing upper layer of the outer membrane. At each longitudinal projection, the site of the greatest thickness, including plaque, was sought along the arterial walls nearest the skin and farthest from the skin from the common carotid artery to the internal carotid artery. Assessments of IMT were conducted three times at the site of the greatest thickness and at two other points, $1 \mathrm{~cm}$ upstream and $1 \mathrm{~cm}$ downstream from this site, and these were then averaged. The greatest value among the six averaged IMTs (each three from the left and the right) was used as the representative value for each individual. All scans were conducted by physicians who were unaware of the clinical characteristics of the subjects. Assessment of IMT on the photograph was carried out by a physician who was unaware of the clinical characteristics of the subjects. The reproducibility of the IMT measurements was examined by conducting another scan 1 month later on 20 subjects with Type II diabetes whose IMT values were 0.68 to $1.39 \mathrm{~mm}$. The mean difference in IMT between these two assessments was $0.04 \mathrm{~mm}$, and the standard deviation was $0.09 \mathrm{~mm}$, showing good reproducibility for repeated measurements, as described previously [21-23].

Genomic analyses. Genomic DNA was prepared from blood leukocytes by established methods. The presence of the missense Glu298Asp variant was examined by PCR-RFLP analysis as described by another study [25]. A set of primers was designed to amplify the 248-base pair (bp) fragment encompassing the missense Glu298Asp variant (the sense and antisense primers $5^{\prime}$-AAGGCAGGAGACAGTGGATGGA-3' ${ }^{\prime}$ and 5'-CCCAGTCAATCCCTTTGGTGCTCA-3', respectively). The PCR fragments were digested with the restriction enzyme Ban II (Toyobo Tokyo, Japan), separated by electrophoresis using low melting temperature agarose gel (4\%, NuSieve GTG AGAROSE, FMC) and visualized by ethidium bromide stain- 
Table 1. Genotype distributions and allele frequencies for the Glu298Asp and -786T-C polymorphism of the eNOS gene in non-diabetic subjects and Type II diabetic patients

\begin{tabular}{|c|c|c|c|c|c|c|}
\hline \multirow[t]{2}{*}{ Glu298Asp polymorphism } & \multicolumn{4}{|c|}{ Genotypes } & \multicolumn{2}{|c|}{ Allele frequencies } \\
\hline & $\mathrm{N}$ & GG & GT & TT & G & $\mathrm{T}$ \\
\hline Non-diabetic subjects ${ }^{a}$ & 233 & $196(84.1 \%)$ & $35(15.0 \%)$ & $2(0.9 \%)$ & 0.916 & 0.084 \\
\hline Type II diabetic patients & 301 & $256(85.0 \%)$ & $42(14.0 \%)$ & $3(1.0 \%)$ & 0.920 & 0.080 \\
\hline \multirow[t]{2}{*}{-786T-C polymorphism } & \multicolumn{4}{|c|}{ Genotypes } & \multicolumn{2}{|c|}{ Allele frequencies } \\
\hline & $\mathrm{N}$ & TT & $\mathrm{TC}$ & $\mathrm{CC}$ & $\mathrm{T}$ & $\mathrm{C}$ \\
\hline Non-diabetic subjectsb & 233 & $194(83.3 \%)$ & $35(15.0 \%)$ & $4(1.7 \%)$ & 0.908 & 0.092 \\
\hline Type II diabetic patients & 301 & $250(83.1 \%)$ & $48(15.9 \%)$ & $3(1.0 \%)$ & 0.910 & 0.090 \\
\hline
\end{tabular}

a "Non-diabetic subjects vs Type II diabetic patients regarding Glu298Asp mutation of eNOS gene": genotypes $\chi^{2}=0.14$, $p=0.93$; allele frequencies $\chi^{2}=0.11, p=0.74$

ing. -786T-C mutation was also examined by PCR-RFLP analysis developed specially for this study. A set of primers was designed to amplify the $236 \mathrm{bp}$ fragment encompassing the 786T-C mutation (the sense and antisense primers $5^{\prime}$-ATGCTCCCACCAGGGCATCA-3' and 5'-GTCCTTGAGTCTGACATTAGGG-3', respectively). The PCR fragments were digested with the restriction enzyme Msp I (Toyobo Co., Japan), separated by electrophoresis using $20 \%$ polyacrylamide gel and visualized by ethidium bromide staining.

NO measurement. We also assessed plasma NO concentrations by measuring the total amount of plasma NO end products (nitrate and nitrite; NOx) as described previously [26, 27]. Specimens of peripheral venous blood from the brachial vein were collected into heparinized tubes after the subjects had been sitting at rest for $15 \mathrm{~min}$ in a quiet room maintained at a temperature of $22{ }^{\circ} \mathrm{C}$ to $24{ }^{\circ} \mathrm{C}$. The blood was placed immediately in an ice bath and centrifuged within $30 \mathrm{sec}$ for $5 \mathrm{~min}$ at $2000 \mathrm{~g}$. The serum fraction was diluted 1:1 with nitrite distilled water and nitrite-free distilled water, and $400 \mathrm{ml}$ of the distilled sample was centrifuged at $2000 \mathrm{~g}$ in an ultra-free MC microcentrifuge device to remove substances larger than $10000 \mathrm{M}_{\mathrm{r}}$. The filtrate was passed through a copper-plated cadmium column to reduce nitrate and nitrite and then reacted with Griess reagents consisting of $0.1 \%$ naphthylethylenediamine dihydrochloride in distilled water and $1 \%$ sulphanilamide in $5 \% \mathrm{H}_{3} \mathrm{PO}_{4}$, after which the absorbance was measured at $540 \mathrm{~nm}$ to evaluate the total amount of plasma NO end products (nitrate and nitrite). The efficacy of the cadmium column in the conversion of nitrate to nitrite was confirmed to be $100 \%$ by measuring both nitrate and nitrite standards before and after sample measurement [26].

Statistical analyses. Data are shown as means \pm SD. Deviation from Hardy-Weinberg equilibrium was examined by chisquared analysis. The clinical characteristics of the subjects were analysed by the genotypes of the Glu298Asp and -786T-C polymorphisms as follows: difference in quantitative variables were examined by one-way ANOVA and differences in frequencies were examined by chi-square analysis. The difference in genotype or allele frequency between non-diabetic subjects and Type II diabetic patients was examined by chi-square analysis. All analyses were conducted using the HALBAU statistical package (Gendai Sugakusha, Kyoto, Japan). b "Non-diabetic subjects vs type II diabetic patients regarding -786T-C mutation of $e N O S$ gene": genotypes $\chi^{2}=0.59, p=0.74$; allele frequencies $\chi^{2}=0.024, p=0.88$

$\chi^{2}$ analysis was carried out

\section{Results}

Genotype distributions and allele frequencies in nondiabetic subjects and type II diabetic patients are shown in Table 1. Genotype distributions and allele frequencies of both Glu298Asp and -786T-C polymorphisms in non-diabetic subjects and Type II diabetic patients were in accordance with the Hardy-Weinberg equilibrium. With the Glu298Asp polymorphism, there was no difference of allele frequency between Japanese non-diabetic subjects and Type II diabetic patients. Concerning -786T-C mutation, there is no difference of allele frequency between Japanese nondiabetic subjects and Type II diabetic patients. In each polymorphism, the number of homozygous mutants was so small that we combined the data of homozygous and heterozygous mutants in the following analysis.

The clinical characteristics associated with Glu298Asp polymorphism of the eNOS gene in the 233 non-diabetic subjects and 301 Type II diabetic patients are shown in Table 2. In the non-diabetic subjects, no difference was noted between those with and without the mutation with respect to clinical characteristics, such as fasting plasma insulin and HOMA IR. The results of a euglycaemic hyperinsulinemic clamp done on the 71 Type II diabetic patients are shown in Table 3. GIR in those with the mutation showed a tendency of impaired insulin-mediated glucose uptake compared with those without the mutation $\left(4.67 \pm 1.04\right.$ vs $\left.5.65 \pm 1.83 \mathrm{mg} \cdot \mathrm{kg}^{-1} \cdot \mathrm{min}^{-1}, p=0.092\right)$, although the difference was not statistically significant.

Clinical characteristics associated with -786T-C mutation of the eNOS gene in the 233 non-diabetic subjects and 301 Type II diabetic subjects are shown in Table 4. In non-diabetic subjects, those with the mutation showed higher fasting plasma insulin 
Table 2. Clinical characteristics according to Glu298Asp (G894T) polymorphism of eNOS gene

\begin{tabular}{|c|c|c|c|c|c|c|}
\hline & \multicolumn{3}{|c|}{ Non-diabetic subjects } & \multicolumn{3}{|c|}{ Type II diabetic patients } \\
\hline & GG & GT or TT & $p$ & GG & GT or TT & $p$ \\
\hline Age (years) & $43.9 \pm 10.5$ & $42.0 \pm 11.0$ & 0.315 & $57.6 \pm 10.6$ & $55.8 \pm 12.3$ & 0.322 \\
\hline BMI $\left(\mathrm{kg} / \mathrm{m}^{2}\right)$ & $22.5 \pm 2.9$ & $22.0 \pm 3.0$ & 0.374 & $23.7 \pm 3.9$ & $23.7 \pm 4.8$ & 0.980 \\
\hline Systolic BP (mmHg) & $122 \pm 12$ & $121 \pm 13$ & 0.579 & $133 \pm 16$ & $133 \pm 18$ & 0.943 \\
\hline Total cholesterol (mmol/1) & $5.01 \pm 0.76$ & $4.99 \pm 0.64$ & 0.894 & $5.25 \pm 0.99$ & $5.20 \pm 0.74$ & 0.750 \\
\hline Triglycerides (mmol/l) & $1.15 \pm 0.51$ & $0.98 \pm 0.43$ & 0.070 & $1.53 \pm 0.82$ & $1.39 \pm 0.68$ & 0.304 \\
\hline HDL cholesterol (mmol/1) & $1.57 \pm 0.36$ & $1.55 \pm 0.34$ & 0.786 & $1.33 \pm 0.39$ & $1.33 \pm 0.35$ & 0.920 \\
\hline Insulin (pmol/l) & $43.6 \pm 17.0$ & $44.0 \pm 17.3$ & 0.901 & - & - & \\
\hline $\mathrm{HOMA}_{\mathrm{IR}}$ & $1.66 \pm 0.69$ & $1.75 \pm 0.74$ & 0.502 & - & - & \\
\hline IMT (mm) & $0.96 \pm 0.23$ & $0.98 \pm 0.24$ & 0.800 & $1.26 \pm 0.44$ & $1.25 \pm 0.40$ & 0.888 \\
\hline Nephropathya & - & - & & $228 / 28$ & $36 / 9$ & - \\
\hline Retinopathy ${ }^{\mathrm{a}}$ & - & - & & $213 / 43$ & $38 / 7$ & - \\
\hline Treatment of diabetes ${ }^{a}$ & - & - & & $64 / 101 / 91$ & $9 / 16 / 20$ & - \\
\hline
\end{tabular}

a $\chi^{2}$ test

Means \pm SD

NOx, plasma nitrate and nitrite levels; HT-Risk, number of subjects with either systolic $>160$, diastolic pressure $>95 \mathrm{mmHg}$, or taking anti-hypertensive drugs; HL-Risk, number of subjects with either total cholesterol $>5.69 \mathrm{mmol} / \mathrm{l}$, triglyceride $>1.70 \mathrm{mmol} / \mathrm{l}$, HDL-cholesterol $<1.03 \mathrm{mmol} / \mathrm{l}$ or taking hypolipidaemic drugs, SM-Risk, number of subjects who smoke more than one pack of cigarettes per day for 20 years; Nephropathy, normoalbuminuria + albuminuria / proteinuria with normal serum creatinine; Retinopathy, no diabetic retinopathy + background diabetic retinopathy/preproliferative diabetic retinopathy + proliferative diabetic retinopathy; Treatment of diabetes, diet therapy / oral agents / insulin injection

Table 3. Results of euglycaemic hyperinsulinaemic clamp among 71 Type II diabetic patients

\begin{tabular}{|c|c|c|c|c|c|c|}
\hline & \multicolumn{3}{|c|}{ Glu298Asp (G894T) polymorphism } & \multicolumn{3}{|c|}{-786T-C polymorphism } \\
\hline & GG & GT or TT & $p$ & TT & $\mathrm{TC}$ or $\mathrm{CC}$ & $p$ \\
\hline Sex (male/female) & $48 / 15$ & $4 / 4$ & - & $42 / 15$ & $10 / 4$ & - \\
\hline Age (years) & $52 \pm 12$ & $49 \pm 16$ & 0.494 & $52 \pm 13$ & $49 \pm 12$ & 0.562 \\
\hline BMI $\left(\mathrm{kg} / \mathrm{m}^{2}\right)$ & $25.2 \pm 5.4$ & $26.0 \pm 6.4$ & 0.668 & $25.8 \pm 5.6$ & $25.2 \pm 5.4$ & 0.723 \\
\hline $\mathrm{HbA}_{1 \mathrm{c}}(\%)$ & $6.9 \pm 1.6$ & $7.8 \pm 0.9$ & 0.221 & $7.2 \pm 1.9$ & $7.8 \pm 1.3$ & 0.281 \\
\hline Glucose infusion rate $(\mu \mathrm{mol} / \mathrm{kg} / \mathrm{min})$ & $31.4 \pm 10.2$ & $25.9 \pm 5.8$ & 0.092 & $31.6 \pm 10.6$ & $24.3 \pm 5.0$ & 0.025 \\
\hline
\end{tabular}

Data are means $\pm \mathrm{SD}$

(49.8 \pm 16.8 vs $42.4 \pm 16.8 \mathrm{pmol} / \mathrm{l}, p=0.019)$ and HOMA IR $(1.89 \pm 0.68$ vs $1.63 \pm 0.69, p=0.043)$ than those without the mutation. In Type II diabetic patients, those with the mutation show a higher $\mathrm{HbA}_{1 \mathrm{c}}(8.3 \pm 2.0$ vs $7.6 \pm 1.6 \%, p=0.006$ ) and a lower plasma NOx concentration (20.2 \pm 7.5 vs $25.8 \pm 8.2 \mu \mathrm{mol} / 1, p=0.026)$ than those without the mutation. The Type II diabetic patients with the $-786 \mathrm{C}$ mutation showed a lower insulin-mediated glucose uptake than those without the mutation $\left(4.38 \pm 0.90\right.$ vs $5.68 \pm 1.90 \mathrm{mg} \cdot \mathrm{kg}^{-1} \cdot \mathrm{min}^{-1}$, $p=0.025$ ) (Table 3). Those with and without the mutation showed no differences of other clinical characteristics and diabetic microangiopathy and macroangiopathy including the urinary secretion rate of albu- $\min$ and IMT $(1.29 \pm 0.37$ vs $1.25 \pm 0.45 \mathrm{~mm}, p=0.592)$ (Table 4).

\section{Discussion}

This study showed that $-786 \mathrm{~T}-\mathrm{C}$ mutation of the eNOS gene is associated with a higher plasma insulin and HOMA IR in non-diabetic subjects. Also, diabetic patients with this mutation possessed a higher $\mathrm{HbA}_{1 \mathrm{c}}$ and a lower plasma NOx concentration. The euglycaemic hyperinsulinemic clamp study showed a lower insulin-mediated glucose uptake in those with -786T-C mutation, although the number of patients 
Table 4. Clinical characteristics according to -786T-C polymorphism of eNOS gene

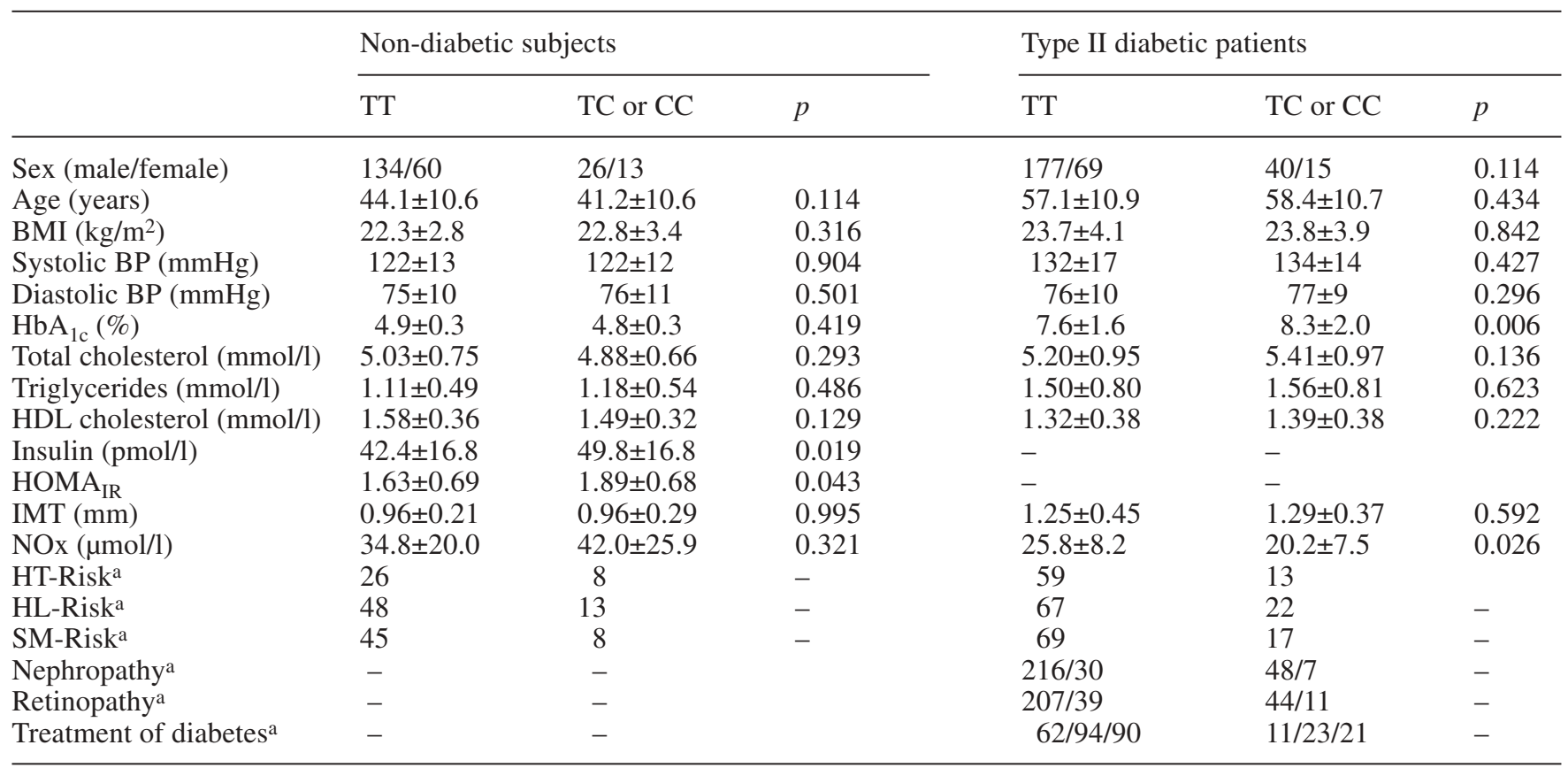

${ }^{2}$ test

Means \pm SD

NOx, plasma nitrate and nitrite levels; HT-Risk, number of subjects with either systolic $>160$, diastolic pressure $>95 \mathrm{mmHg}$, or taking anti-hypertensive drugs; HL-Risk, number of subjects with either total cholesterol $>5.69 \mathrm{mmol} / \mathrm{l}$, triglyceride $>1.70 \mathrm{mmol} / \mathrm{l}$, HDL-cholesterol $<1.03 \mathrm{mmol} / \mathrm{l}$ or taking hypolipidaemic drugs; SM-Risk, number of subjects who smoke more than one pack of cigarettes per day for 20 years; Nephropathy, normoalbuminuria + albuminuria / proteinuria with normal serum creatinine; Retinopathy, no diabetic retinopathy + background diabetic retinopathy/preproliferative diabetic retinopathy + proliferative diabetic retinopathy; Treatment of diabetes, diet therapy / oral agents / insulin injection studied was limited due to the difficulty of obtaining informed consent. We did not carry out a euglycaemic hyperinsulinaemic clamp with non-diabetic subjects as this would not have been ethical. Concerning Glu298Asp polymorphism, the non-diabetic subjects showed no difference in clinical characteristics and the Type II diabetic patients showed no difference in the insulin-mediated glucose uptake with the euglycaemic hyperinsulinaemic clamp, although there was a tendency of slightly lower values in the mutant groups.

The mechanisms of these two polymorphisms affecting eNOS activity are different. Glu298Asp polymorphism induces the structural change of the eNOS protein and reduces $e N O S$ activity $[10,11]$. In contrast, a different study showed that in -786T-C mutation, replication protein $\mathrm{A} 1$ which is known as a DNA binding protein essential for DNA repair and replication, binds only to the mutant allele and reduces the promoter activity of the eNOS gene [12, 28]. This could cause -786T-C mutation leading to a profound impairment of vasodilation, which could result in impaired insulin-mediated glucose uptake in the whole body. A recent study indicated that in smokers -786C homozygote shows a decrease of cerebrovascular circulation [29]. Our study showed that the Glu298Asp mutation had a tendency of impaired insulin-mediated glucose uptake (Table 3). A previous report has shown that both -786T-C mutation and Glu298Asp are associated with vasoconstrictive angina $[12,15]$. Multiple logistic regression analysis suggests that -786T-C mutation is more closely associated with vasoconstrictive angina than Glu298Asp polymorphism [30]. Our study agreed with this multiple regression analysis. Thus, it is likely that $-786-\mathrm{C}$ mutation rather than Glu298Asp polymorphism is associated with development of insulin resistance as well as vasoconstrictive angina, although we cannot exclude the possibility that the Glu298Asp polymorphism could have some less obvious effects on insulin resistance.

In this study, we measured NOx concentration, which is the plasma end products of NO, because the lifetime of NO is quite short and cannot be measured directly as a real time value. The Type II diabetic patients showed a lower plasma NOx concentration than non-diabetic subjects $(23.9 \pm 8.2$ vs $42.3 \pm 31.5 \mu \mathrm{mol} / \mathrm{l}$, $p=0.00003)$. There is increasing evidence that NO synthesis and the vasodilating properties of insulin are impaired in insulin resistant states, such as Type II diabetes and obesity [31, 32]. Thus, our data agree with previous findings [33]. In the 301 Type II diabetic patients, the mutant group of -786T-C polymorphism showed a higher $\mathrm{HbA}_{1 \mathrm{c}}$ than the non-mutant 
group. These data agree with the idea that $-786 \mathrm{~T}-\mathrm{C}$ polymorphism impairs endothelial NO production, leading to a decrease in insulin-mediated glucose uptake through impaired vasodilatation and poor glycaemic control.

The non-diabetic subjects with the -786T-C mutation showed no difference in NOx concentration. One possibility is that non-diabetic subjects show a large SD of NOx concentration compared to Type II diabetic patients (20.9 vs $8.2 \mu \mathrm{mol} / 1$, respectively). Especially, non-diabetic females aged $35.4 \pm 11.2$ years also showed a higher NOx concentration and its wider variation than those of Type II diabetic females aged $58.7 \pm 10.5$ years $(36.7 \pm 20.8$ vs $17.5 \pm 4.1 \mu \mathrm{mol} / \mathrm{l})$. Oestrogen has been shown to increase eNOS activity [34]. NOx as well as oestrogen could fluctuate during the menstrual cycle in pre-menopausal females. In this study, however, we did not consider the menstrual cycle when we obtained blood samples from female subjects. The other possibility is that non-diabetic females tended to have a higher NOx concentration than non-diabetic males $(26.6 \pm 14.0 \mu \mathrm{mol} / \mathrm{l})$. These factors as well as other unknown factors could neglect the effect of eNOS mutation on NOx concentration in non-diabetic subjects.

Regarding Glu298Asp polymorphism of the eNOS gene, we found no differences in plasma NOx concentrations, clinical characteristics and insulin-mediated glucose uptake (only in the diabetic patients) between those with and without mutant alleles in both nondiabetic subjects and diabetic patients. Thus, these data agree well with the hypothesis that the Glu298Asp mutation is not strong enough to affect clinical characteristics and insulin-mediated glucose uptake.

We also examined the possible association between two eNOS polymorphisms and diabetic nephropathy and retinopathy. There are several reports showing the association of -786T-C polymorphism and diabetic nephropathy $[35,36]$, and there is a report showing the dissociation of Glu298Asp polymorphism and diabetic nephropathy [37]. In this study, there was no difference in the number of patients taking an ACE inhibitor, which has been reported to reduce urinary protein. We found no association between diabetic microangiopathy and these polymorphisms. We are trying to evaluate the effect of these polymorphisms on the onset of diabetic complications in a larger number of patients.

Another important role of NO in the vasculature is its antiatherogenic effects by scavenging superoxide radicals and suppression of platelet aggregation, leukocyte adhesion and smooth muscle cell proliferation [38-40]. In this study we assessed IMT as an index of early atherosclerosis. There are several reports showing the association of Glu298Asp polymorphism and myocardial infarction [25, 41, 42]. On the other hand, there are inconsistencies according to
European reports examining the association of Glu298Asp polymorphism and carotid atherosclerosis $[43,44]$, and there has been no report about the association of -786T-C polymorphism and carotid atherosclerosis. In this study, we found no relation between these polymorphisms and IMT. These results could be due to genetic differences among ethnic groups and the progression of atherosclerosis might be affected by various factors other than eNOS activities such as NADH/NADPH oxidase, inflammatory cytokine, and monocyte chemoattractant protein-1.

Our study shows that the relative allele frequencies of Glu298Asp and -786T-C polymorphism of the eNOS gene do not differ between Japanese nondiabetic subjects and Type II diabetic patients. Considering that both insulin resistance and impaired insulin secretion play a major role in the onset of Type II diabetes, one possibility is that $-786 \mathrm{~T}-\mathrm{C}$ polymorphism does not affect the susceptibility of Type II diabetes. Another possibility is that non-diabetic subjects were younger than the Type II diabetic patients and thus some subjects with this mutation might have been in a pre-diabetic state.

The frequency of the 894T allele in Japanese nondiabetic subjects $(0.084)$ is similar to that found in Japanese control subjects of other studies [25, 45], but is lower than that found in the control subjects in a European study (0.44) [46]. The frequency of the -786C allele in Type II diabetic patients in this study (0.09) is similar to that found in Japanese control subjects of another study $[12,45]$, but is lower than that found in American Type I diabetic patients without progressive nephropathy (0.36) [35]. No corresponding data are available for European or American control subjects and Type II diabetic patients such comparative studies are needed.

Those who had both mutant alleles were 4 out of 233 non-diabetic subjects and 3 out of 301 Type II diabetic patients (data not shown) and these frequencies were less than expected (non-diabetic subjects:6.2, Type II diabetic patients:7.6). This might deny the linkage disequilibrium between the Glu298Asp and -786T-C polymorphism of the eNOS gene. These findings agree with those of another report [30]. We could not detect any specific clinical characteristics among those with both mutant alleles.

In conclusion, our study shows that -786T-C polymorphism of the eNOS gene is associated with insulin resistance both in Japanese non-diabetic subjects and Type II diabetic patients.

Acknowledgements. We would like to thank Y. Sasaki for her excellent technical assistance. We are deeply indebted to numerous medical doctors and paramedic personnel for their assistance in managing patients with Type II diabetes at Osaka University Hospital. 


\section{References}

1. Baron AD, Steinberg H, Brechtel G et al. (1994) Skeletal muscle blood flow independently modulates insulin-mediated glucose uptake. Am J Physiol. 266: E248-E253

2. Baron AD, Brechtel-Hook G, Johnson A, Cronin J, Leaming R, Steinberg HO (1996) Effect of perfusion rate on the time course of insulin-mediated skeletal muscle glucose uptake. Am J Physiol 271: E1067-E1072

3. Baron AD, Steinberg HO, Chaker H, Leaming R, Johnson A, Brechtel G (1995) Insulin-mediated skeletal muscle vasodilation contributes to both insulin sensitivity and responsiveness in lean humans. J Clin Invest 96: 786-792

4. Serne EH, Stehouwer CD, ter Maaten JC et al. (1999) Microvascular function relates to insulin sensitivity and blood pressure in normal subjects. Circulation 99: 896-902

5. Baron AD, Tarshoby M, Hook G et al. (2000) Interaction between insulin sensitivity and muscle perfusion on glucose uptake in human skeletal muscle: evidence for capillary recruitment. Diabetes 49: 768-774

6. Utriainen T, Makimattila S, Virkamaki A, Bergholm R, Yki-Jarvinen H (1996) Dissociation between insulin sensitivity of glucose uptake and endothelial function in normal subjects. Diabetologia 39: 1477-1482

7. Laine H, Yki-Jarvinen H, Kirvela O et al. (1998) Insulin resistance of glucose uptake in skeletal muscle cannot be ameliorated by enhancing endothelium-dependent blood flow in obesity. J Clin Invest 101: 1156-1162

8. Shankar RR, Wu Y, Shen HQ, Zhu JS, Baron AD (2000) Mice with gene disruption of both endothelial and neuronal nitric oxide synthase exhibit insulin resistance. Diabetes 49: 684-687

9. Duplain H, Burcelin R, Sartori C et al. (2001) Insulin resistance, hyperlipidemia, and hypertension in mice lacking endothelial nitric oxide synthase. Circulation 104: 342-345

10. Wang XL, Sim AS, Wang MX, Murrell GA, Trudinger B, Wang J (2000) Genotype dependent and cigarette specific effects on endothelial nitric oxide synthase gene expression and enzyme activity. FEBS Lett 471: 45-50

11. Tesauro M, Thompson WC, Rogliani P, Qi L, Chaudhary PP, Moss J (2000) Intracellular processing of endothelial nitric oxide synthase isoforms associated with differences in severity of cardiopulmonary diseases: cleavage of proteins with aspartate vs. glutamate at position 298. Proc Natl Acad Sci U S A 97: 2832-2835

12. Nakayama M, Yasue H, Yoshimura M et al. (1999) $\mathrm{T}-786->\mathrm{C}$ mutation in the $5^{\prime}$-flanking region of the endothelial nitric oxide synthase gene is associated with coronary spasm. Circulation 99: 2864-2870

13. Philip I, Plantefeve G, Vuillaumier-Barrot S et al. (1999) G894T polymorphism in the endothelial nitric oxide synthase gene is associated with an enhanced vascular responsiveness to phenylephrine. Circulation 99: 3096-3098

14. Yoshimura M, Nakayama M, Shimasaki Y et al. (2000) A T-786C mutation in the $5^{\prime}$-flanking region of the endothelial nitric oxide synthase gene and coronary arterial vasomotility. Am J Cardiol 85: 710-714

15. Yoshimura M, Yasue H, Nakayama M et al. (1998) A missense Glu298Asp variant in the endothelial nitric oxide synthase gene is associated with coronary spasm in the Japanese. Hum Genet 103: 65-69

16. World Health Organisation (1980) WHO Expert Committee on Diabetes Mellitus: second report. WHO Technical Report Series No 646, World Health Organisation, Geneva

17. Marshall SM (1991) Screening for microalbuminuria: which measurement ? Diabet Med 8: 706-711
18. Matthews DR, Hosker JP, Rudenski AS, Naylor BA, Treacher DF, Turner RC (1985) Homeostasis model assessment: insulin resistance and beta-cell function from fasting plasma glucose and insulin concentrations in man. Diabetologia 28: 412-419

19. DeFronzo RA, Tobin JD, Andres R (1979) Glucose clamp technique: a method for quantifying insulin secretion and resistance. Am J Physiol 237: E214-E223

20. Yamasaki Y, Kawamori R, Wasada T et al. (1997) Pioglitazone (AD-4833) ameliorates insulin resistance in patients with NIDDM. AD-4833 Glucose Clamp Study Group, Japan. Tohoku J Exp Med 183: 173-183

21. Kawamori R, Yamasaki Y, Matsushima H et al. (1992) Prevalence of carotid atherosclerosis in diabetic patients. Ultrasound high-resolution B-mode imaging on carotid arteries. Diabetes Care 15: 1290-1294

22. Yamasaki Y, Kawamori R, Matsushima H et al. (1994) Atherosclerosis in carotid artery of young IDDM patients monitored by ultrasound high-resolution B-mode imaging. Diabetes 43: 634-639

23. Yamasaki Y, Kawamori R, Matsushima H et al. (1995) Asymptomatic hyperglycaemia is associated with increased intimal plus medial thickness of the carotid artery. Diabetologia 38: 585-591

24. Pignoli P (1984) Ultrasound B-mode imaging for arterial wall thickness measurement. Atheroscler Rev 12: 177184

25. Shimasaki Y, Yasue H, Yoshimura M et al. (1998) Association of the missense Glu298Asp variant of the endothelial nitric oxide synthase gene with myocardial infarction. J Am Coll Cardiol 31: 1506-1510

26. Green LC, Wagner DA, Glogowski J, Skipper PL, Wishnok JS, Tannenbaum SR (1982) Analysis of nitrate, nitrite and [15 N] nitrate in biological fluids. Anal Biochem 126: 131138

27. Node K, Kitakaze M, Yoshikawa H, Kosaka H, Hori M (1997) Reduced plasma concentrations of nitrogen oxide in individuals with essential hypertension. Hypertension 30: 405-408

28. Miyamoto Y, Saito Y, Nakayama M et al. (2000) Replication protein A1 reduces transcription of the endothelial nitric oxide synthase gene containing a $-786 \mathrm{~T}->\mathrm{C}$ mutation associated with coronary spastic angina. Hum Mol Genet 9: 2629-2637

29. Nasreen S, Nabika T, Shibata H et al. (2002) T-786C polymorphism in endothelial NO synthase gene affects cerebral circulation in smokers: possible gene-environmental interaction. Arterioscler Thromb Vasc Biol 22: 605-610

30. Yoshimura M, Yasue H, Nakayama M et al. (2000) Genetic risk factors for coronary artery spasm: significance of endothelial nitric oxide synthase gene T-786->C and missense Glu298Asp variants. J Investig Med 48: 367374

31. Laakso M, Edelman SV, Brechtel G, Baron AD (1992) Impaired insulin-mediated skeletal muscle blood flow in patients with NIDDM. Diabetes 41: 1076-1083

32. Cleland SJ, Petrie JR, Small M et al. (2000) Insulin action is associated with endothelial function in hypertension and type 2 diabetes. Hypertension 35: 507-511

33. Kurioka S, Koshimura K, Murakami Y, Nishiki M, Kato Y (2000) Reverse correlation between urine nitric oxide metabolites and insulin resistance in patients with type 2 diabetes mellitus. Endocr J 47: 77-81

34. Weiner CP, Lizasoain I, Baylis SA et al. (1994) Induction of calcium-dependent nitric oxide synthases by sex hormones. Proc Natl Acad Sci USA 91: 5212-5216 
35. Zanchi A, Moczulski DK, Hanna LS, Wantman M, Warram JH, Krolewski AS (2000) Risk of advanced diabetic nephropathy in type 1 diabetes is associated with endothelial nitric oxide synthase gene polymorphism. Kidney Int 57: 405-413

36. Neugebauer S, Baba T, Watanabe T (2000) Association of the nitric oxide synthase gene polymorphism with an increased risk for progression to diabetic nephropathy in type 2 diabetes. Diabetes 49: 500-503

37. Ukkola O, Erkkila PH, Savolainen MJ, Kesaniemi YA (2001) Lack of association between polymorphisms of catalase, copper-zinc superoxide dismutase (SOD), extracellular SOD and endothelial nitric oxide synthase genes and macroangiopathy in patients with type 2 diabetes mellitus. J Intern Med 249: 451-459

38. Moncada S, Higgs A (1993) The L-arginine-nitric oxide pathway. N Engl J Med 329: 2002-2012

39. Schmidt HH, Walter U (1994) NO at work. Cell 78: 919 925

40. Radomski MW, Palmer RM, Moncada S (1987) Endogenous nitric oxide inhibits human platelet adhesion to vascular endothelium. Lancet ii: $1057-1068$
41. Hibi K, Ishigami T, Tamura K et al. (1998) Endothelial nitric oxide synthase gene polymorphism and acute myocardial infarction. Hypertension 32: 521-526

42. Hingorani AD, Liang CF, Fatibene J et al. (1999) A common variant of the endothelial nitric oxide synthase (Glu298->Asp) is a major risk factor for coronary artery disease in the UK. Circulation 100: 1515-1520

43. Markus HS, Ruigrok Y, Ali N, Powell JF (1998) Endothelial nitric oxide synthase exon 7 polymorphism, ischemic cerebrovascular disease, and carotid atheroma. Stroke 29: 1908-1911

44. Lembo G, De Luca N, Battagli C (2001) A common variant of endothelial nitric oxide synthase (Glu298Asp) is an independent risk factor for carotid atherosclerosis. Stroke 32: 735-740

45. Tsujita Y, Baba S, Yamauchi R (2001) Association analyses between genetic polymorphisms of endothelial nitric oxide synthase gene and hypertension in Japanese: The Suita Study. J Hypertens 19: 1941-1948

46. Lacolley P, Gautier S, Poirier O, Pannier B, Cambien F, Benetos A (1998) Nitric oxide synthase gene polymorphisms, blood pressure and aortic stiffness in normotensive and hypertensive subjects. J Hypertens 16: 31-35 